\title{
Conditioning- and time-dependent increases in context fear and generalization
}

\author{
Andrew M. Poulos, ${ }^{1,2}$ Nehali Mehta, ${ }^{2}$ Bryan Lu, ${ }^{2}$ Dorsa Amir, ${ }^{2}$ Briana Livingston, ${ }^{2}$ \\ Anthony Santarelli, ${ }^{1}$ Irina Zhuravka, ${ }^{2}$ and Michael S. Fanselow ${ }^{2,3}$ \\ ${ }^{1}$ Department of Psychology and Center for Neuroscience, University at Albany, State University of New York, Albany, New York 12222, \\ USA; ${ }^{2}$ Department of Psychology; ${ }^{3}$ Department of Psychiatry, University of California, Los Angeles, Los Angeles, California 90095, USA
}

\begin{abstract}
A prominent feature of fear memories and anxiety disorders is that they endure across extended periods of time. Here, we examine how the severity of the initial fear experience influences incubation, generalization, and sensitization of contextual fear memories across time. Adult rats were presented with either five, two, one, or zero shocks ( $1.2 \mathrm{~mA}, 2 \mathrm{sec})$ during contextual fear conditioning. Following a recent $(1 \mathrm{~d})$ or remote $(28 \mathrm{~d})$ retention interval all subjects were returned to the original training context to measure fear memory and/or to a novel context to measure the specificity of fear conditioning. Our results indicate rats that received two or five shocks show an "incubation"-like enhancement of fear between recent and remote retention intervals, while single-shocked animals show stable levels of context fear memory. Moreover, when fear was tested in a novel context, 1 and 2 shocked groups failed to freeze, whereas five shocked rats showed a time-dependent generalization of context memory. Stress enhancement of fear learning to a second round of conditioning was evident in all previously shocked animals. Based on these results, we conclude that the severity or number of foot shocks determines not only the level of fear memory, but also the time-dependent incubation of fear and its generalization across distinct contexts.
\end{abstract}

Fear memories have a unique set of mnemonic features that may promote the development and onset of anxiety disorders. These include: longevity, incubation, sensitization, and generalization. Here we explored the hypothesis that these properties emerge when the original stressful experience is more intensely fear provoking. To test this hypothesis in rats, we manipulated the level of fear by altering the number of foot shocks.

Survival from environmental threat such as predation requires the rapid, enduring, and specific allocation of defensive behaviors (Bolles 1970). These features are evident in rodent models of fear conditioning as the number and intensity of foot shocks (Fanselow and Bolles 1979; Fanselow 1980, 1984; Young and Fanselow 1992; Maren et al. 1994), the ability to discriminate environmental contexts (Zhou and Riccio 1996; Biedenkapp and Rudy 2007; Wiltgen and Silva 2007; Xu and Sudhof 2013), and the retention interval (Pickens et al. 2013) can greatly influence fear expression. The extent to which the level of fear and the memory retention interval interact may yield important insights into the development of post-traumatic stress disorder (PTSD).

PTSD is a complex of persistent somatic, cognitive, affective, and behavioral changes following trauma (Van der Kolk et al. 1996). A hallmark feature of PTSD is an intense and recurrent emotional memory of trauma (Bernsten and Rubin 2006), which can be triggered by nonspecific environmental stimuli loosely related to the initial trauma. Some accounts suggest that PTSD can have a delayed onset (Freuh et al. 2009), which is consistent with the notion that aversive memories can "incubate" or intensify (Diven 1937; Eysenck 1968; Pickens et al. 2009a). Conversely, it is well established that detailed memories, even those established within emotional contexts with time, are prone to partial forgetting and retrieval error (Riccio et al. 1992). These

\section{Corresponding author: apoulos@albany.edu}

Article is online at http://www.learnmem.org/cgi/doi/10.1101//m.041400. 115. two seemingly contradictory phenomenon may promote a myriad of debilitating time-dependent memory-related effects of aversive experience, including recurrent emotional memories and fear generalizing to extra-traumatic situations leading to more pronounced symptomatology and less efficacious exposure-based therapies.

The use of Pavlovian fear conditioning in rodents has yielded important insights into the mnemonic features of PTSD. In recent years, several studies have demonstrated in rodents, as in humans, that fear memories are more prone to generalize over time as a result of stimulus discrimination failure (Biedenkapp and Rudy 2007; Wiltgen and Silva 2007). This in large part has been attributed to the forgetting of specific contextual-spatial features resulting in the broadening or generalization of fear across distinct contexts (Jasnow et al. 2012). In contrast, demonstrations of fear incubation in the rodent Pavlovian fear conditioning preparation have been more sparse, with a large body of research failing to observe incubation across rodent strains and conditioning parameters (Frankland et al. 2004; Gale et al. 2004; Poulos et al. 2009), yet a series of reports by Pickens and colleagues (2009a,b, 2010) have reported fear incubation with significant modification of standard fear conditioning procedures. At present very little is known about the experimental conditions that promote temporal-dependent changes in fear expression (e.g., incubation and generalization).

Stress enhanced fear learning (SEFL) is another outcome of prior exposure to repeated foot shocks (Rau and Fanselow 2009; Perusini et al. 2016) in which future fear responses to foot shock

(C) 2016 Poulos et al. This article is distributed exclusively by Cold Spring Harbor Laboratory Press for the first 12 months after the full-issue publication date (see http://learnmem.cshlp.org/site/misc/terms.xhtml). After 12 months, it is available under a Creative Commons License (AttributionNonCommercial 4.0 International), as described at http://creativecommons. org/licenses/by-nc/4.0/. 
are sensitized. In light of this, fear incubation maybe an enduring outcome of an extended conditioning-to-retention interval that may further potentiate SEFL. As of yet, collectively little is known on how fear incubation and varying the initial level of stress may impact SEFL.

The present study examines how the number of aversive foot shocks as both an effective stressor and key conditioning parameter affects time-dependent fear memory retention, generalization, and sensitization in the order described in Figure 1. Briefly, foot shock number was varied by use of a one, two, or five foot shock contextual fear conditioning procedure. The retention interval between conditioning and retention were represented by tests of recent and remote long-term memory at 1 and $28 \mathrm{~d}$, respectively. At these time points context generalization was tested in a novel context, while in experiment 2 SEFL was assessed following context extinction procedures. We hypothesized that across this extended conditioning-to-retention interval that remote contextual fear memories are prone to fear "incubation" and contextual generalization. If so, this raises the possibility that context generalization results from an incubation-dependent increase in peak levels of fear, rather than altering the generalization gradient (Bouton et al. 1999; but see Riccio et al. 1999). Moreover, this time-dependent increase in fear may promote an enhanced capacity to sensitize future fear learning.

\section{Results}

\section{Experiment 1: memory retention and generalization}

Overall, rats receiving foot shocks froze more in context A than nonshocked control animals with the level of freezing increasing with the number of foot shocks $\left(F_{(2,54)}=19.112, P<0.001\right)$, as can be seen in Figure 2. Although rats tested at the later memory retention (28 d) interval froze more than at the earlier retention ( $1 \mathrm{~d}$ ) interval $\left(F_{(1,54)}=6.093, P<0.05\right)$ this resulted in a reliable inter-
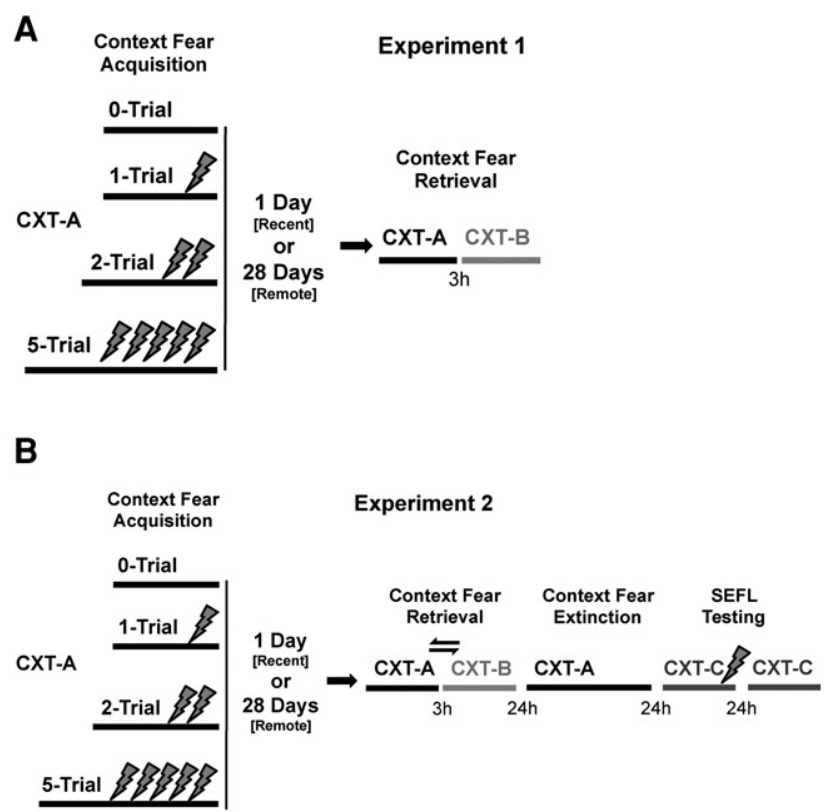

Figure 1. Study and research design for experiments 1 and 2. In experiment $1(A)$ subjects were conditioned with zero, one, two, or five foot shocks then tested for retention and generalization following a 1 or 28 d-retention interval. Experiment $2(B)$ expanded upon this by counterbalancing the order of the memory retention and generalization tests, as well as observing extinction and sensitization to novel contexts daily following the initial retrieval tests.

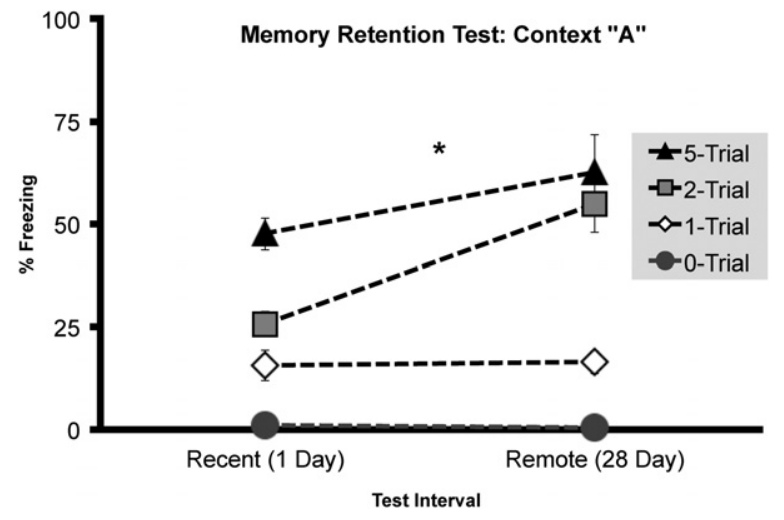

Figure 2. Experiment 1, contextual fear memory (context A) measured at either 1 or $28 \mathrm{~d}$ following initial fear conditioning by either zero, one, two, or five foot shocks. Total mean percentage of time spent freezing ( \pm SEM) during a 4-min context fear test. Asterisks $\left({ }^{*}\right)$ represents significance at the $P<0.05$ criterion.

action between Shock number and Retention interval $\left(F_{(2,54)}=\right.$ $3.824, P<0.05)$. Whereas, a single shock yielded a temporally stable context fear memory with similar levels of freezing at $1(N=$ $10, M=20.9, \mathrm{SEM}=6.36)$ and $28 \mathrm{~d}(N=10, M=16.4, \mathrm{SEM}=$ $2.83)$, two shocks resulted in an "incubation" like increase in freezing at the $28(N=10, M=54.8, S E M=6.79)$ versus $1 \mathrm{~d}$ $(N=10, M=29.1915$, SEM $=4.41)$ retention interval. This pattern of fear incubation was again evident with five shocks as mean freezing was marginally greater and more variable at the $28(N=10, M=62.7, S E M=9.20)$ than at the $1-d(N=10$, $M=47.616, \mathrm{SEM}=3.91)$ retention interval. A planned comparison independent samples $T$-test confirmed that animals fear conditioned with two shocks $\left(t_{(18)}=-3.162, P<0.01\right)$ showed an increase in freezing from 1 to $28 \mathrm{~d}$, whereas neither $1\left(t_{(18)}=\right.$ $3.066 P=0.524)$ nor five shocks $\left(t_{(18)}=-1.509 P=0.157\right)$ groups froze more across this memory retention interval. The high levels of freezing in the five shock group could have obscured incubation through a ceiling effect or the greater variability in freezing in this group may have limited our ability to detect incubation.

In general, as shown in Figure 3, rats tested in context B froze more at the 28 - versus 1 -d retention interval $\left(F_{(1,30)}=4.749, P<\right.$ $0.05)$. This was particularly evident in two- and five-shock conditioned groups as freezing increased across day 1 (two-trial: $N=7$,

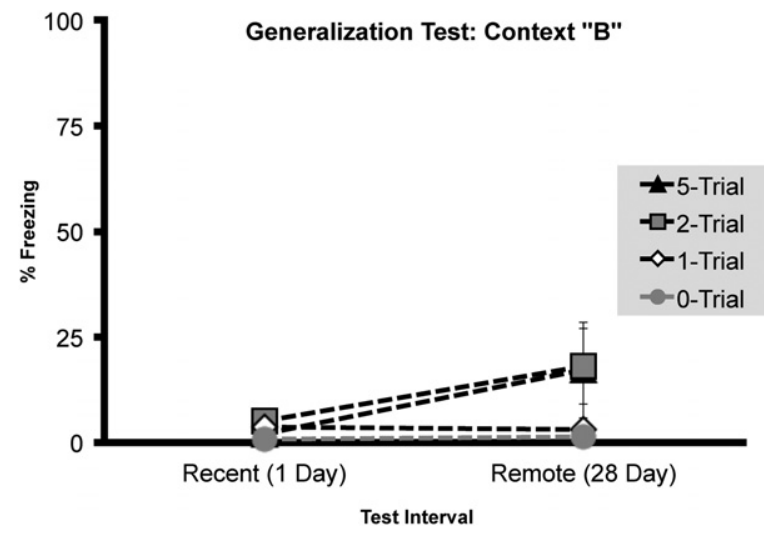

Figure 3. Experiment 1, context generalization (context $\mathrm{B}$ ) measured at either 1 or $28 \mathrm{~d}$ following initial fear conditioning by either zero, one, two, or five foot shocks. Total mean percentage of time spent freezing ( \pm SEM) during a 4-min context generalization test. 
$M=4.98, \mathrm{SEM}=2.72,5$-trial: $N=8, M=2.03, \mathrm{SEM}=0.62$ ) to day 28 (2-trial: $N=4, M=18.06, \mathrm{SEM}=11.27$; five-trial: $N=6, M=$ 17.08, SEM =9.06). However, both 1 - and nonshocked groups failed to freeze in context $B$ at either retention interval ( 1 day: mean freezing range $0 \%-3.6 \%$; $28-\mathrm{d}$ : mean freezing range $1.48 \%-2.9 \%)$. In light of this, no main effect of Shock number was detected $\left(F_{(2,30)}=1.331, P=0.279\right)$. A planned comparison independent samples $T$-test found no significant differences in generalized freezing in context $\mathrm{B}$ at 28 versus 1 - $\mathrm{d}$ retention interval in groups conditioned with $1 \quad\left(t_{(9)}=0.261 P=0.80\right), 2$ $\left(t_{(10)}=-1.532 P=0.157\right)$, and 5 trials $\left(t_{(11)}=-1.802 P=0.099\right)$.

\section{Experiment 2: generalization, extinction, and SEFL}

Experiment 2 further examined context generalization, extinction, and SEFL (1B). To control for potential effects of testing order between generalization and context fear testing, we counterbalanced order of this testing within a single day (3-h apart).

Overall, freezing in context A was dependent on Shock number $\left(F_{(2,111)}=27.603, P<0.001\right)$ and Retention interval $\left(F_{(1,111)}=5.505, P<0.05\right)$ with no reliable interaction. Once again, 1 shock conditioning yielded a temporally stable context fear memory with similar levels of freezing at $1(N=24, M=$ 40.736, SEM $=5.058)$ and 28 days $(N=15, M=44.412, \mathrm{SEM}=$ 7.679). Although the "incubation effect" established in experiment 1 was replicated in the two shocked conditioned group and was extended to the five shock group, wherein both groups displayed greater freezing (Fig. 4) across the 1 day (two trials: $N=22, M=63.77, \operatorname{SEM}=4.83$; five trials: $N=24, M=76.68$, SEM $=4.93)$ to 28 retention interval (2-trials: $N=16, M=82.03$, SEM $=4.41 ; 5$-trials: $N=16, M=91.39, \mathrm{SEM}=3.03)$. A planned comparison using Fisher's Independent samples $T$-test confirmed that animals conditioned with 2 and 5, but not one shock significantly froze more at the $28 \mathrm{~d}$ than the 1 -d retention interval (two trial: $t_{(36)}=2.681, P<0.05 ; 5$ trial: $t_{(38)}=2.245, P<0.05$; one trial: $t_{(37)}=0.417, P=0.679$ ) (Fig. 4).

Three hours prior to or following context memory retention testing, subjects were placed in a novel conditioning box, context $\mathrm{B}$, to test for context fear generalization (Fig. 5). Shock number $\left(F_{(2,88)}=15.720, \quad P<0.001\right)$ and Retention interval $\left(F_{(1,88)}=\right.$ $16.295, P<0.001)$ reliably increased generalized freezing in context $B$, which resulted in a reliable interaction between Shock number and Retention interval $\left(F_{(2,88)}=5.782, P<0.01\right)$.

Results of experiment 2 confirmed that single-shocked animals did not generalize as indicated by a lack of freezing in context

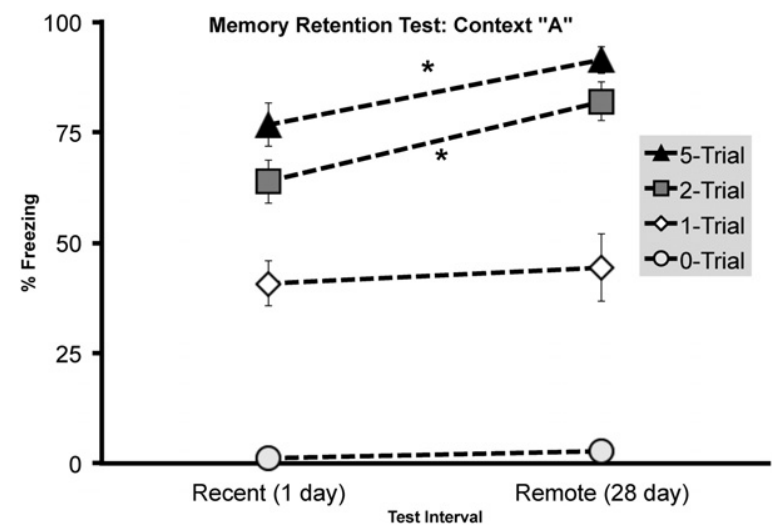

Figure 4. Experiment 2, contextual fear memory (context A) measured at either 1 or $28 \mathrm{~d}$ following initial fear conditioning by either one, two, or five foot shocks. Total mean percentage of time spent freezing ( \pm SEM) during a 4 -min context fear test. Asterisks $\left(^{*}\right)$ represents significance at the $P<0.05$ criterion.
B at 1 day $(N=16, M=6.70, \operatorname{SEM}=3.04)$ or 28 day $(N=15$, $M=10.37, \mathrm{SEM}=2.44)$ following conditioning. Similarly, two and five shock conditioned subjects showed low levels of generalization at the 1-d retention interval (two shock: $N=15$, $M=16.5, \mathrm{SEM}=5.52$; five-shock: $N=16, \quad M=19.13, \mathrm{SEM}=$ 5.62). However, generalized freezing was evident at the 28 -d retention interval in the two- $(N=16, M=27.342$, SEM = 6.329) and five-trial conditioned groups $(N=16, M=56.486$, $\mathrm{SEM}=6.696)$. An independent samples $T$-test confirmed an increase in generalized freezing at 28-d versus 1 -d retention interval in five shock conditioned animals $\left(t_{(30)}=4.2700, P<0.001\right)$. In experiment 2 , both generalization and incubation resulted from a main effect of Retention interval and Shock number, which could indicate generalization resulted from an overall incubation-dependent increase in freezing.

\section{Context discrimination}

To determine the influence of fear incubation upon context generalization, a context discrimination ratio (context $\mathrm{A} /$ (context $\mathrm{A}+$ context B)) was computed for each subject tested in both context A (shocked context) and context B (unshocked context) (Fig. 6). A $2 \times 3$ ANOVA detected a main effect of Retention interval $\left(F_{(1,88)}=10.286, P=0.002\right)$, but not Shock number $\left(F_{(1,88)}=\right.$ $2.845, P=0.063)$. Animals conditioned with five shocks had reduced levels of context discrimination at the 28-d $(N=16$, $M=0.6342$, SEM $=0.0323$ ) as compared with the 1-d retention interval $(N=16, M=0.8377, \operatorname{SEM}=0.03625)$, which was confirmed by an independent samples $T$-test $\left(t_{(30)}=4.1894, P<\right.$ 0.001). Discrimination ratios confirmed independent of fear incubation that freezing in context B was consistent with a temporal-dependent alteration in the generalization gradient.

\section{Context extinction}

The day following fear memory and generalization testing, subjects were reexposed to the original fear conditioned context $\mathrm{A}$ for a 20-min context extinction session (Fig. 7), which revealed a within-session reduction of conditional freezing $\left(F_{(9,1017)}=\right.$ 23.179, $P<0.001$ ) with a significant interaction with Shock number $\left(F_{(18,1017)}=4.645, P<0.001\right)$, but neither main effects for Retention interval $\left(F_{(9,1017)}=0.229, P=0.990\right)$ nor interactions of Retention interval $\times$ Shock number $\left(F_{(18,1017)}=0.883, P=\right.$ $0.60)$ were detected. Fear incubation was again evident during context extinction, a between subject analysis revealed main effects of Retention interval $\left(F_{(1,113)}=12.591, P<0.001\right)$, Shock number $\left(F_{(2,113)}=19.118, P<0.001\right)$ as well as a significant interaction $\left(F_{(2,113)}=3.744, P<0.05\right)$. Independent sample $T$-tests confirmed that freezing levels under extinction were elevated at the remote as compared with the recent retention interval in multishock (five shock: $P<0.001$; two shock: $P<0.001$ ), but not in singly shocked animals $(P>0.05)$.

\section{Stress enhancement of fear learning}

All groups with prior foot shock experience, exhibited enhanced fear learning in context $\mathrm{C}$ as compared to unshocked controls (Fig. 8). Such impressions were revealed by a $2 \times 4$ ANOVA of freezing, which indicated a main effect of prior Shock number $\left(F_{(3,147)}=34.913, P<0.001\right)$ but not Retention interval $\left(F_{(1,147)}=1.267, P>0.05\right)$. This was confirmed by an LSD post hoc analysis as one-shock $(P<0.001)$, two-shock $(P<0.001)$, and five-shock conditioning $(P<0.001)$ resulted in enhanced fear conditioning relative to nonshocked subjects. To compare levels of sensitization across time for subjects given different number of conditioning trials, a planned comparison independent sample $T$-tests was performed. Although no differences in the 


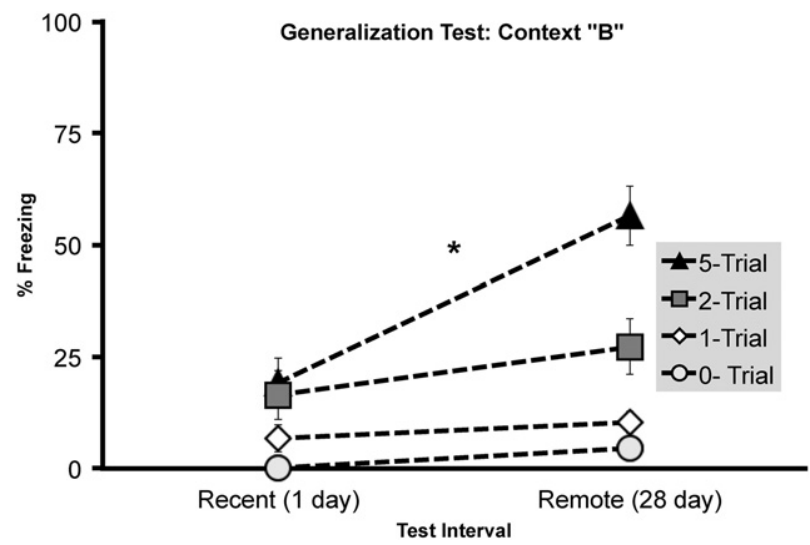

Figure 5. Experiment 2, context generalization (context B) measured at either 1 or $28 \mathrm{~d}$ following initial fear conditioning by either one, two, or five foot shocks. Total mean percentage of time spent freezing ( \pm SEM) during a 4-min context generalization test. Asterisks $\left(^{*}\right)$ represents significance at the $P<0.05$ criterion.

level of SEFL across time were detected in previously unshocked $\left(t_{(0.689)}=-0.184 P=0.854\right)$, two $\left(t_{(2.736)}=0.183 P=0.856\right)$ and five shock $\left(t_{(0.083)}=-0.150 P=0.881\right)$ conditioned groups, oneshock conditioning resulted in a time-dependent attenuation of fear sensitization $28 \mathrm{~d}$ out $\left(t_{(0.222)}=2.722 P<0.01\right)$.

\section{Discussion}

Fear is a highly adaptive response to perceived environmental threat. In fear conditioning, the level of freezing is tightly regulated by the amount of aversive reinforcement. Two examples of this regulation are that freezing is graded to the intensity of foot shock as measured in electrical current (Fanselow and Bolles 1979; Fanselow 1980, 1984; Young and Fanselow 1992; Maren et al. 1994) and the number of foot shocks received (Fanselow and Bolles 1979). This was evident here, as context freezing $1 \mathrm{~d}$ following conditioning was directly proportional to the number of foot shocks received. The level of freezing in singly shocked rats was retained across a remote 28 -d retention interval. However, rats conditioned with multiple foot shocks and tested at the remote retention interval displayed heightened context fear

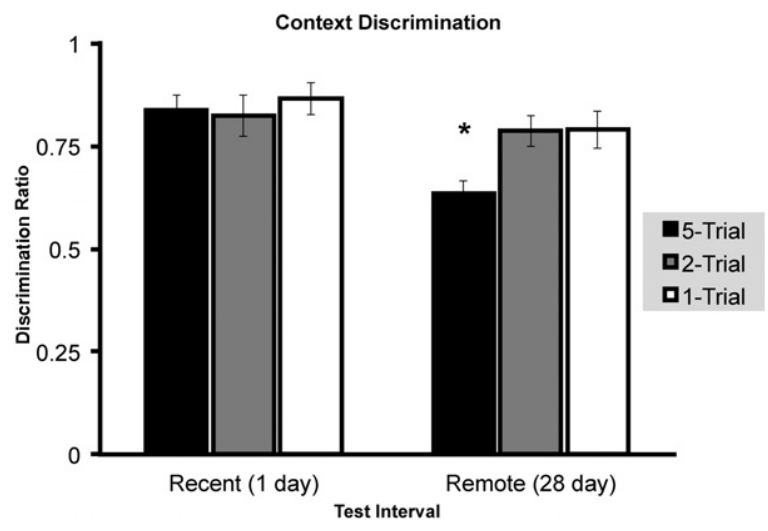

Figure 6. Experiment 2, context discrimination ratio (context $A$ freezing/(context $A+$ context $B$ freezing)) ( \pm SEM) computed from animals conditioned by either one, two, or five foot shocks measured either 1 or $28 \mathrm{~d}$ following the initial conditioning. Asterisks $\left({ }^{*}\right)$ represents significance at the $P<0.05$ criterion. that approached ceiling levels of freezing. For the most part, the context freezing in single-shocked rats was specific to the conditioned context regardless of when testing occurred. However, rats that received five foot shocks showed poorer differentiation between the previously conditioned and novel context resulting in generalized context fear.

In the present experiment, context fear expression in rats trained with minimal one-shock conditioning yielded a low level of fear (Figs. 2, 4) that remained stable, while repeatedly shocked rats displayed an increase in fear across the extended memory retention interval. This pattern in multitrial conditioned animals is consistent with evidence of incubation using overtraining with an auditory CS (8-100 trials), spaced over multiple days ( 2 or $10 \mathrm{~d}$ ) and/or under food deprivation (Houston et al. 1999; Pickens et al. 2010). Here, we demonstrate using a more reduced conditioning preparation that a single trial does not yield fear incubation, but two conditioning trials within a single session were sufficient to generate a time dependent increase in context fear expression. In line with this, Balogh et al. (2002) and Balogh and Wehner (2003) using two parings of a clicker-CS and foot shocks revealed context elicited fear incubation in several strains of mice. These and our present results seem to conflict with several prior studies comparing recent and remote context fear retrieval, which have failed to demonstrate fear incubation (Kim and Fanselow 1992; Anagnostaras et al. 1999; Frankland et al. 2004). However, those studies used more shock than used here and it is possible that learning/performance reached ceiling levels that would hinder the ability to observe fear incubation.

An important consideration is whether context generalization results from an increase in peak freezing levels (Bouton et al. 1999) or a temporal-dependent flattening of the generalization gradient (Riccio et al. 1999). In the present study, significant freezing began to generalize outside the initial training context at longer retention intervals, when freezing levels peaked. To reduce the influence of higher levels of context A freezing upon generalized context B freezing, as would be expected with fear incubation, discrimination ratios (combining experiments 1 and 2) revealed that five, but not one or two trials yielded a timedependent reduction of context discrimination. Our results in Long-Evans rats are consistent with prior studies in mice (Wiltgen and Silva 2007; Wiltgen et al. 2010) examining timedependent effects on contextual fear discrimination and further indicate that shock number is a key variable, as multiple but not single-trial conditioning alters the slope of the generalization

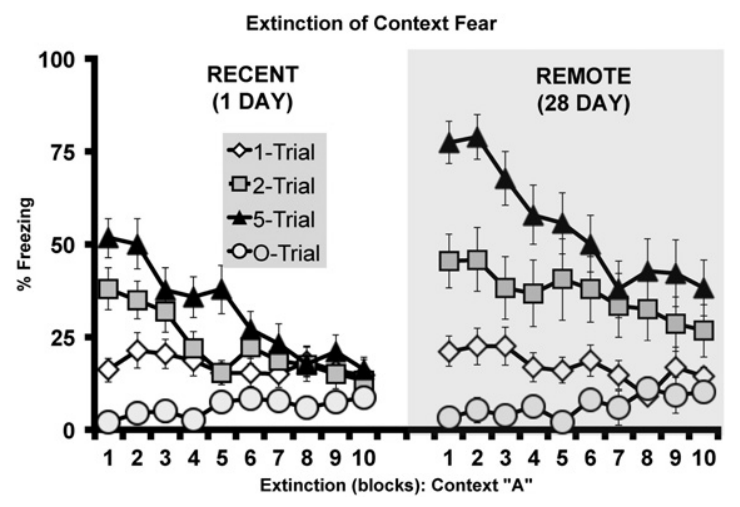

Figure 7. Experiment 2, extinction of context fear (context A) measured at either 1 or $28 \mathrm{~d}$ following initial fear conditioning by one, two, or five foot shocks. Twenty minute extinction session were conducted $1 \mathrm{~d}$ following the retrieval and generalization tests. Each block represents a 2-min interval of the mean percent time spent freezing ( \pm SEM) during the extinction session. 


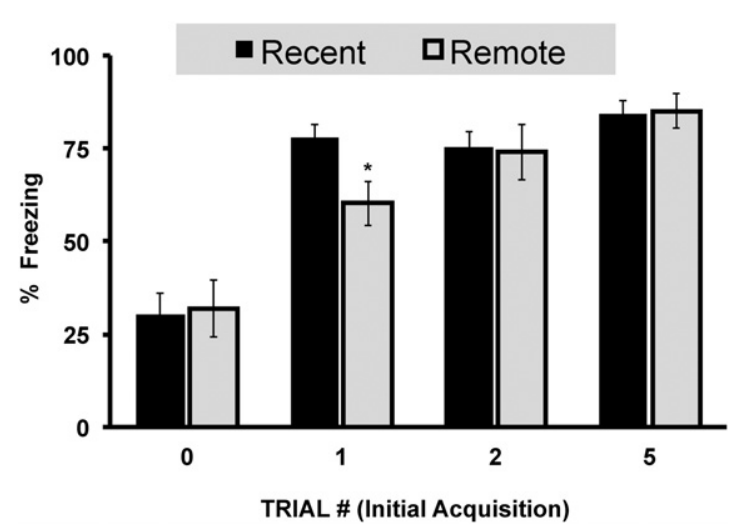

Figure 8. Experiment 2, stress enhancement of fear (context C) measured at $2 \mathrm{~d}$ following context extinction training in subjects initially tested at either 1 or $28 \mathrm{~d}$ following initial fear conditioning by either zero, one, two, or five foot shocks. Total mean percentage of time spent freezing ( \pm SEM) during a 4-min context fear test. Asterisks $\left(^{*}\right)$ represents significance at the $P<0.05$ criterion.

gradient. However, it is possible that remote freezing levels in context A with multiple conditioning trials could be limited by ceiling effects that may skew our discrimination ratios.

During context fear extinction, fear incubation was again evident in multitrial conditioned tested rats. Although all recently tested rats eventually extinguished to the same level, remote animals conditioned with multiple trials failed to reach a point of extinction exemplified by one-trial conditioned subjects or its recently conditioned counterparts. This pattern of within-session extinction of older fear-related memories might suggest that the efficacy of extinction maybe impacted by the passage of time. Though remote memories are more prone to fear incubation, both recent and remote context extinction within a single session progressed at a similar rate (Fig. 7). One assumption of the present results is at earlier retention time-points, incubation is incomplete and continues to increase fear expression to at least 28 $\mathrm{d}$. This predicts that remote fear memories that undergo repeated extinction sessions might occur unimpeded by the antagonistic actions of fear incubation. However, more recent fear memories bound to the influence of fear incubation are more prone to failures of extinction retrieval that may include reinstatement, spontaneous recovery and renewal. Indeed, a recent study by Corcoran et al. (2013) found that recently extinguished context fears are more prone to the effects of reinstatement than remotely extinguished contexts. Other studies examining the time-dependent effects of memory and extinction have focused on auditory fear extinction at shorter times scales from minutes to a few days (Myers et al. 2006; Maren and Chang 2006). Further studies examining fear incubation may lend important insights into how context fear and time can modulate the extinction of cued and contextual fear responses observed in renewal and spontaneous recovery effects.

We have previously demonstrated that the SEFL effect, resulting from prior exposure to repeated, but not a single foot shock (1.0 $\mathrm{mA}$ ) enhances future fear conditioning up to 3 mo following the initial shock experience (Rau and Fanselow 2009). Here we demonstrate, using a stronger foot shock intensity $(1.2 \mathrm{~mA})$ that a single shock stressor is capable of producing SEFL regardless of whether the shock experience occurred at a recent $(3 \mathrm{~d})$ or a remote $(31 \mathrm{~d})$ interval. These intervals had no bearing on the level of SEFL in previous multishocked animals, however singleshocked rats displayed a modest temporal-dependent decrement of SEFL. This may suggest, that SEFL under limited shock experi- ence is prone to weakening as a function of time. A similar effect obtained by Carew and colleagues in Aplysia suggest that unlike multiple siphon shocks, a single shock fails to produce long-term sensitization (Sutton et al. 2002). Interestingly, the one-shock animals were the only group that displayed a stable fear memory that did not incubate or for that matter, generalize. It remains possible that the observed incubation effect in two and five-shocked groups could play a facilitatory role in SEFL. Future studies could address this by using lower foot shock intensities to minimize ceiling levels of SEFL-related freezing (Poulos et al. 2015).

It has been estimated that people afflicted with PTSD seek treatment, $12 \mathrm{yr}$ from the onset of the initial symptoms (Wang et al. 2005). This delay in seeking initial treatment and the prevalence of delayed onset PTSD (Andrews et al. 2009) suggest that time-dependent mechanisms may contribute to reaching a symptomatic threshold and/or initial treatment contact. This simple rodent model may address some of these factors by experimentally manipulating the severity of aversive experience (number of foot shocks) and the interval of time between trauma-to-symptom characterization. Here we show that under conditions of greater aversive experience and with the passage of time that fear intensifies and begins to emerge outside of the initial fear conditioned environment.

Collectively, the present findings establish both procedural and behavioral parameters that are amenable to neural systems analysis of four clinically relevant outcomes of fear conditioning: incubation, generalization, sensitization, and resistance to extinction. Last, the present results suggest that as severity of aversive experiences along with an extended post-shock period increases, so does expression of fear memory-related PTSD symptoms.

\section{Materials and Methods}

\section{Subjects}

A total of 199 adult male Long-Evans rats purchased from a commercial vendor (Harlan, Indianapolis, IN) were used in the following experiments. At the beginning of the experiment, rats were between 70 and $85 \mathrm{~d}$ old and weighed $250-300 \mathrm{~g}$. Rats were individually housed on a 14:10 light-dark cycle with free access to food and water. All animals were habituated to handling for 1-2 min every day for a week prior to experimentation. All experimental procedures were in accordance with the Animal Research Committee at the University of California, Los Angeles.

\section{Apparatus}

Conditioning Apparatus: four rats were concurrently run in individual conditioning boxes housed in light and sound attenuating chambers. The conditioning boxes were accessories of a Near Infra-Red (NIR) Video Fear Conditioning System (Med Associates Inc., Georgia, VT). Each conditioning box was configured to represent one of three training contexts that differed in internal structure, floor texture, illumination, and odor. Context A $(28 \times$ $21 \times 21 \mathrm{~cm}$ ) had a clear Plexiglas back wall, ceiling, and front door with aluminum sidewalls. The grid floor consisted of evenly spaced and stainless steel rods. Context A was cleaned with 70\% ethanol and scented with 50\% Simple Green. Context B also had a clear Plexiglas back wall, ceiling, and door with aluminum sidewalls. The inner structure of the chamber was altered through the addition of triangular opaque black Plexiglas sidewalls at an angle of $60^{\circ}$ to the floor. The floors of context B consisted of white, acrylic flooring cleaned and odored with $1 \%$ acetic acid solution. Context C consisted of white curved sidewalls that extended across the back wall. The floors were evenly spaced grid bars, alternating in thickness. The context was cleaned and odored with Windex. The floor in context $\mathrm{A}$ and $\mathrm{C}$ were connected to a shocking apparatus, which delivered a scrambled foot shock. 


\section{Measure of freezing}

Freezing was measured using the Video Freeze software (Med Associates) included in the NIR Video Fear Conditioning System. The software performed real-time video recordings (30 frames per second) using a set threshold level validated to human scored freezing. Context fear, generalization, and sensitization were quantified as the percent time the animal spent freezing in a given context.

\section{Experiment 1: memory retention and generalization}

Subjects $(n=80)$ were evenly and randomly assigned one of four context fear acquisition groups: no shock $(n=20)$, one shock $(n=20)$, two shocks $(n=20)$, or five shocks $(n=20)$.

Figure 1A summarizes the general design of experiment 1. Context fear acquisition in context A consisted of a 3-min preshock period followed by zero, one, two, or five foot shocks ( 2 sec, $1.2 \mathrm{~mA}$ ) spaced 1-min apart and ending with a 1-min postshock period. One or $28 \mathrm{~d}$ after acquisition, recent and remote context fear memories were tested, respectively, which consisted of returning animals to the original acquisition context (context A) for $4 \mathrm{~min}$. The following day, some animals from both groups were placed in novel context B for a 4 min to test of context fear generalization.

\section{Experiment 2: generalization, extinction, and SEFL}

Figure $1 \mathrm{~B}$ summarizes the general design of experiment 2 . This experiment consisted of the similar groups and conditions to experiment $1(n=119)$, but counterbalanced the order of context $A$ and context B testing, added a single session of context extinction (20 min) and an assessment of SEFL. One or $28 \mathrm{~d}$ following acquisition, half of the subjects were first exposed to context A (4 min) then $3 \mathrm{~h}$ later exposed to context $\mathrm{B}(4 \mathrm{~min})$, whereas in the remaining animals the order of testing was counterbalanced to minimize potential confounds of order effects. The next day, all animals were returned to context A for a 20-min context extinction session. The day following extinction, animals were placed in context $C$ for a SEFL trial. This consisted of a 3 -min preshock baseline followed by a 2-sec 1-mA shock and a 1-min post-shock period. The following day animals were then brought back to context C for a 4-min SEFL test.

\section{Statistical analysis}

A multivariate analysis of variance (MANOVA) was used to evaluate the levels of freezing observed across retention intervals in response to shock number (one, two, or five foot shocks). In experiment 2 , a discrimination ratio was computed (fear memory/[fear memory + fear generalization]) to infer differences associated with freezing in context $\mathrm{A}$ and generalized freezing in context B. Two subjects were removed from the analysis in experiment 2 , one as a univariate outlier $(z=-3.33183, P<0.01)$ and the other as a multivariate outlier (Mahal $=26.607, P<0.001$ ). Following the primary analysis, Fisher's $T$-tests were conducted to investigate the effects of retention interval within each shock number. An omnibus multivariate significance test revealed an interaction between retention interval and shock number (Wilk's $=$ $\left.0.843, F_{(6,172)}=2.564, P=0.021\right)$. All multivariate tests were confirmed by univariate ANOVA.

\section{Acknowledgments}

This work was supported by the National Institute of Mental Health Grant MH62122 (M.S.F). We thank Dr. Ravikumar Ponnusamy and Dr. Maxine Reger for their thoughtful discussions and comments during the design and completion of the experiments described in this manuscript.

\section{References}

Anagnostaras SG, Maren S, Fanselow MS. 1999. Temporally graded retrograde amnesia of contextual fear after hippocampal damage in rats: within-subjects examination. J Neurosci 19: 1106-1114.

Andrews B, Brewin CR, Stewart L, Philpott R, Hejdenberg J. 2009. Comparison of immediate-onset and delayed-onset posttraumatic stress disorder in military veterans. J Abnorm Psychol 118: 767-777.

Balogh SA, Wehner JM. 2003. Inbred mouse strain differences in the establishment of long-term fear memory. Behav Brain Res 140: 97-106.

Balogh SA, Radcliffe RA, Logue SF, Wehner JM. 2002. Contextual and cued fear conditioning in C57BL/6J and DBA/2J mice: context discrimination and the effects of retention interval. Behav Neurosci 116: 947-957.

Bernsten D, Rubin DC. 2006. Flashbulb memories and posttraumatic stress reactions across life span: age-related effects of the German occupation of Denmark during World War II. Psychol Aging 21: 127-129.

Biedenkapp JC, Rudy JW. 2007. Context preexposure prevents forgetting of a contextual fear memory: implication for regional changes in brain activation patterns associated with recent and remote memory tests. Learn Mem 14: 200-203.

Bolles RC. 1970. Species-specific defense reactions and avoidance learning. Psychol Rev 77(1): 32-48.

Bouton ME, Nelson JB, Rosas JM. 1999. Stimulus generalization, context change and forgetting. Psychol Bull 125: 171-186.

Corcoran KA, Leaderbrand K, Radulovic J. 2013. Extinction of remotely acquired fear depends on an inhibitory NR2B/PKA pathway in the retrosplenial cortex. J Neurosci 33: 19492-19498.

Diven K. 1937. Certain determinants in the conditioning of anxiety reactions. J Psychol 3: 291-308.

Eysenck HJ. 1968. A theory of the incubation of anxiety/fear responses. Behav Res Therapy 6: 309-321.

Fanselow MS. 1980. Conditioned and unconditioned components of post-shock freezing. Pav J Biol Sci 15: 177-182.

Fanselow MS. 1984. Opiate modulation of the active and inactive components of the postshock reaction: parallels between naloxone pretreatment and shock intensity. Behav Neurosci 98: 269-277.

Fanselow MS, Bolles RJ. 1979. Naloxone and shock-elicited freezing in the rat. I Comp Physiol Psychol 93: 736-744.

Frankland PW, Bontempi B, Talton LE, Kaczmarek L, Silva AJ. 2004. The involvement of the anterior cingulate cortex in remote contextual fear memory. Science 304: 881-883.

Freuh BC, Grubaugh AL, Yeager DE, Magruder KM. 2009. Delayed-onset post-traumatic stress disorder among war veterans in primary care clinics. Br J Psychiatry 194: 515-520.

Gale GD, Anagnostaras SG, Godsil BP, Mitchell S, Nozawa T, Sage JR, Fanselow MS. 2004. Role of the basolateral amygdala in the storage of fear memories across the adult lifetime of rats. J Neurosci 24: $3810-3815$

Houston FP, Stevenson GD, McNaughton BL, Barnes CA. 1999. Effects of age on the generalization and incubation of memory in the F344 rat. Learn Mem 6: 111-119.

Jasnow AM, Cullen PK, Riccio DC. 2012. Remembering another aspect of forgetting. Front Psychol 3: 175.

Kim JJ, Fanselow MS. 1992. Modality-specific retrograde amnesia of fear. Science. 256: 675-677.

Maren S, Chang C. 2006. Recent fear is resistant to extinction. Proc Nat Acad Sci 103: 18020-18025.

Maren S, De Oca B, Fanselow MS. 1994. Sex differences in hippocampal long-term potentiation (LTP) and Pavlovian fear conditioning in rats: positive correlation between LTP and contextual learning. Brain Res 661: $25-34$.

Myers KM, Ressler KJ, Davis M. 2006. Different mechanisms of fear extinction dependent on length of time since fear acquisition. Learn Mem 13: 216-223.

Perusini JN, Meyer EM, Long VA, Rau V, Nocera N, Avershal J, Maksymetz J, Spigelman I, Fanselow MS. 2016. Induction and expression of fear sensitization caused by acute traumatic stress. Neuropsychopharmacology 41: $45-57$.

Pickens CL, Adams-Deutsch T, Nair SG, Navarre BM, Heilig M, Shaham Y. 2009a. Effect of pharmacological manipulations of neuropeptide Y and corticotropin-releasing factor neurotransmission on incubation of conditioned fear. Neuroscience 164: 1398-1406.

Pickens CL, Golden SA, Adams-Deutsch T, Nair SG, Shaham Y. $2009 \mathrm{~b}$. Long-lasting incubation of conditioned fear in rats. Biol Psychiatry 65: $881-886$.

Pickens CL, Navarre BM, Nair SG. 2010. Incubation of conditioned fear in the conditioned suppression model in rats: role of food-restriction conditions, length of conditioned stimulus, and generality to conditioned freezing. Neuroscience 169: 1501-1510.

Pickens CL, Golden SA, Nair SG. 2013. Incubation of fear. Curr Protoc Neurosci Chapter 6: Unit 6.27. doi: 10.1002/0471142301. 
Poulos AM, Li V, Sterlace SS, Tokushige F, Ponnusamy R, Fanselow MS. 2009. Persistence of fear memory across time requires the basolateral amygdala complex. Proc Natl Acad Sci 106: 11737-11741.

Poulos AM, Zhuravka I, Long V, Gannam C, Fanselow MS. 2015. Sensitization of fear learning to mild unconditional stimuli in male and female rats. Behav Neurosci 129: 62-67.

Rau V, Fanselow MS. 2009. Exposure to a stressor produces a long lasting enhancement of fear learning in rats. Stress 12: 125-133.

Riccio DC, Ackil J, Burch-Vernon A. 1992. Forgetting of stimulus attributes: methodological implications for assessing associative phenomena. Psychol Bull 112: 433-445.

Riccio DC, Richardson R, Ebner DL. 1999. The contextual change paradox is still unresolved: comment on Bouton, Nelson and Rosas (1999). Psychol Bull 125: 187-189.

Sutton MA, Ide J, Masters SE, Carew TJ. 2002. Interaction between amount and pattern of training in the induction of intermediate- and long-term memory for sensitization in aplysia. Learn Mem 9: 29-40.

Van der Kolk BA, Pelcovitz D, Roth S, Mandel FS, McFarlane A, Herman JL. 1996. Dissociation, somatization, and affect dysregulation: the complexity of adaptation of trauma. Am J Psychiatry 153(7 Suppl): 83-93.
Wang PS, Berglund P, Olfson M, Pincus HA, Wells KB, Kessler RC. 2005. Failure and delay in initial treatment contact after first onset of mental disorders in the National Comorbidity Survey Replication. Arch Gen Psychiatry 62: 603-613.

Wiltgen BJ, Silva AJ. 2007. Memory for context becomes less specific with time. Learn Mem 14: 313-317.

Wiltgen BJ, Zhou M, Cai Y, Balaji J, Karlsson MG, Parivash SN, Li W, Silva AJ. 2010. The hippocampus plays a selective role in the retrieval of detailed contextual memories. Curr Biol 20: 1336-1344.

$\mathrm{Xu}$ W, Sudhof TC. 2013. A neural circuit for memory specificity and generalization. Science 339: 1290-1295.

Young SL, Fanselow MS. 1992. Associative regulation of Pavlovian fear conditioning: unconditional stimulus intensity, incentive shifts, and latent inhibition. J Exp Psychol Anim Behav Process 18: 400-413.

Zhou Y, Riccio DC. 1996. Manipulation of components of context: the context shift effect and forgetting of stimulus attributes. Learn Motiv 27: 400-407.

Received December 14, 2015; accepted in revised form April 12, 2016. 


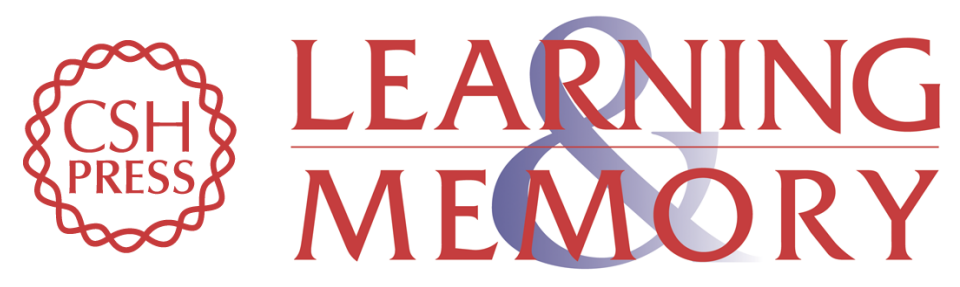

\section{Conditioning- and time-dependent increases in context fear and generalization}

Andrew M. Poulos, Nehali Mehta, Bryan Lu, et al.

Learn. Mem. 2016, 23:

Access the most recent version at doi:10.1101/Im.041400.115

References This article cites 41 articles, 14 of which can be accessed free at: http://learnmem.cshlp.org/content/23/7/379.full.html\#ref-list-1

Creative This article is distributed exclusively by Cold Spring Harbor Laboratory Press for the Commons License first 12 months after the full-issue publication date (see

http://learnmem.cshlp.org/site/misc/terms.xhtml). After 12 months, it is available under a Creative Commons License (Attribution-NonCommercial 4.0 International), as described at http://creativecommons.org/licenses/by-nc/4.0/.

Email Alerting Receive free email alerts when new articles cite this article - sign up in the box at the Service top right corner of the article or click here. 